\title{
PROYECTOS Y REFORMA DE LA IGLESIA DE SANTA MARÍA DE LA REDONDA DE LOGROÑO (LA RIOJA) PARA CONVERTIRLA EN CATEDRAL
}

\author{
Sara Ramírez Maya \\ Universidad de La Rioja
}

\begin{abstract}
RESUMEN: Las obras más importantes ejecutadas en Santa María de la Redonda durante el siglo XIX obedecieron a la intención de que se convirtiese en catedral. Este artículo es un estudio de los proyectos más importantes que articularon esta reforma: el primero realizado por el arquitecto Francisco Enríquez Ferrer en 1853, la modificación del mismo propuesta por Maximiano Hijón en 1880, y el proyecto definitivo realizado conjuntamente por los arquitectos Maximiano Hijón, Francisco de Luis y Tomás y Luis Barrón en 1882.
\end{abstract}

Palabras clave: Arquitectura, conservación, siglo XIX, Logroño, patrimonio, Enríquez Ferrer.

\section{PROJECTS AND REFORM ON THE CHURCH OF SANTA MARÍA DE LA REDONDA IN LOGROÑO (LA RIOJA) TO CONVERT IT IN A CATHEDRAL}

ABSTRACT: The most important constructions made on Santa María de la Redonda during the $19^{\text {th }}$ century were done with the objective of converting Santa María de la Redonda into a cathedral. This article is a study about the most important projects that were the base of the main reform: the first one was carried out by the architect Francisco Enríquez Ferrer in 1853, the modification of this project offered by Maximiano Hijón in 1880 and, finally, the definitive project that was done together by the architects Maximiano Hijón, Francisco de Luis y Tomás and Luis Barrón in 1882.

Keywords: Architecture, maintenance, $19^{\text {th }}$ century, Logroño, heritage, Enríquez Ferrer.

El templo de Santa María de la Redonda, declarada Bien de Interés Cultural en 1931, es uno de los edificios más característicos de Logroño. La particular silueta 
de sus dos torres gemelas permiten reconocerlo desde lejos, pero no son muchos los estudios que se han hecho sobre él. Se conoce relativamente su proceso constructivo hasta el siglo XVIII, cuando se levantaron sus torres, pero no hay mucha información sobre las intervenciones que se realizaron durante el siglo XIX.

Casi todos los estudios publicados sobre esta iglesia han aportado datos sobre su historia, unos más acertados que otros. Uno de ellos es el de Sainz Ripa', quien basándose en el examen de la documentación correspondiente, indica que es en el siglo XIII cuando aparece estructurada como parroquia canónicamente reconocida, aunque las primeras noticias documentadas de la iglesia se remontan a finales del siglo XII. El aumento notable de prestigio que experimentó esta parroquia durante el siglo XIV culminó en 1435 cuando adquirió la categoría de colegiata tras unirse canónicamente con la de San Martín de Albelda, pero no existe documentación sobre la renovación el templo, ya que no será hasta los primeros años del siglo XVI cuando el cabildo se propuso hacerlo².

La iglesia no puede ser anterior a 1510 porque el 10 de agosto el arcediano de Logroño, Martín Ruiz de Munilla, pidió en su testamento que su enterramiento fuera allí e hizo unas donaciones para las obras que, según expresa en el mismo documento, se iban a realizar³. Recientemente, José Gabriel Moya Valgañón aporta datos más precisos sobre el plan original de la construcción de la iglesia tras el conocimiento de nuevos documentos que le llevan a afirmar que las obras fueron comenzadas por Juan de Régil -quien concertó en abril de 1516 ocuparse del nuevo templo- y que fue sustituido por Martín Ruiz de Albiz y San Juan de Arteaga en 1523. Tras la muerte de ambos sin finalizar las obras, se hicieron cargo de ellas Juan Marín y Juan de Acha. Éstas se habrían terminado hacia $1544^{4}$.

Lo construido en aquel momento correspondería, con algunas diferencias, al cuerpo central del templo actual: una iglesia de tres naves de la misma altura -la central más ancha que las laterales- separadas por altos pilares cilíndricos baquetonados que apoyan sobre enormes basas que soportan bóvedas de crucería y cinco tramos, con capillas bajas entre los contrafuertes -cuatro a cada lado- cubiertas con bóvedas de tipo germánico sin cruceros, excepto las capiIlas del primer tramo; con coro bajo en el último tramo de la nave central, y, en

1. SÁINZ RIPA, Eliseo, Santa María de la Redonda. De Iglesia parroquial a iglesia concatedral. Siglos XII-XX, Logroño, Instituto de Estudios Riojanos, 1992, 2ª ed. corr. y aum. 2002.

2. La historiografía tradicional mantenía que la iglesia era del siglo XV, excepto Moya Valgañón, que fue el primero en asegurar que la construcción del templo tuvo lugar entre 15001532 (MOYA VALGAÑÓN, José Gabriel, Inventario artístico de Logroño y su provincia, Tomo II, Madrid, Ministerio de Cultura, 1976, p. 298).

3. SÁINZ RIPA, Eliseo, Santa María de la Redonda. De Iglesia parroquial a iglesia concatedral. Siglos XII-XX, Logroño, Instituto de Estudios Riojanos, 1992, 2aㅡ ed. corr. y aum. 2002, pp. 65-81.

4. MOYA VALGAÑÓN, José Gabriel, "De nuevo sobre la Redonda", Berceo, 164, Logroño, 2013, pp. 179-213. 
el lado contrario, tres ábsides poligonales de tres paños, de los que actualmente sólo existe el central.

A comienzos del siglo XVII su coro alto se transformó en bajo, donde se instaló la sillería, realizada a mediados del siglo XVI por Juan de Lorena y Arnao de Bruselas, con reja y trascoro rehechos en el siglo XVIII. También a principios del XVII, se construyó la capilla del Santo Cristo, tomando como centro el testero de la nave de la epístola. Se fundó en 1625 por el obispo Pedro González del Castillo, que encomendó su construcción a dos de los canteros más relevantes del momento en La Rioja ${ }^{5}$. Entre finales del XVII y principios del XVIII se construyó la sacristía y antesacristía tras el ábside de la nave del evangelio, que limitaba al sur con la capilla del Santo Cristo, y se erigieron las dos puertas laterales de acceso al templo.

A los pies del templo, la capilla de los Ángeles y las torres que rematan su fachada hacia la Plaza del Mercado, son una intervención del siglo XVIII, siguiendo trazas de José Raón. Su construcción comenzó el 18 de agosto de 1742 y finalizó en agosto de $1756^{6}$. Por su parte, las obras de la capilla de Nuestra Señora de los Ángeles y estaban terminadas el 22 de junio de 1762, día en el que el cabildo acordó tres días de festejos para celebrar su finalización?

A últimos del siglo XIX, la cabecera sufrió una importante remodelación producto del plan de habilitación del templo como catedral de Francisco Enríquez Ferrer y cuya ejecución, tras algunas modificaciones del plan original en un proyecto conjunto de los arquitectos Maximiano Hijón, Francisco de Luis y Tomás y Luis Barrón, fue la construcción de la girola, lo que implicó la desaparición de la antesacristía y una gran transformación del aspecto de la capilla del Santo Cristo.

Las primeras gestiones para llevar a cabo esta última reforma comenzaron con el nombramiento mediante real orden del 24 de mayo de 1852 del arquitecto Francisco Enríquez Ferrer para que se trasladase a Logroño y examinase los templos de Santiago el Real y de Santa María de la Redonda y propusiera el más adecuado para sede episcopal, eligiendo el de la Redonda.

Este encargo estaba vinculado al Concordato de 1851 firmado después de duras negociaciones por el papa Gregorio XVI y la Reina Isabel II, fruto del acercamiento entre Iglesia y Estado. Entre sus 46 artículos, el que afectó directamente a la diócesis de Calahorra fue el 5º: por un lado, por la creación de la nueva dió-

5. RAMÍREZ MARTíNEZ, José Manuel, Guía histórico-artística de Logroño, Logroño, Ochoa, 1994, p. 154.

6. SÁINZ RIPA, Eliseo, Santa María de la Redonda. De Iglesia parroquial a iglesia concatedral. Siglos XII-XX, Logroño, Instituto de Estudios Riojanos, 1992, 2ª ed. corr. y aum. 2002, p. 193.

7. Ibídem, p. 195. 
cesis de Vitoria y, por otro, porque se establecía que la silla episcopal debía trasladarse a Logroño cuando en esa ciudad todo estuviese dispuesto a tal efecto ${ }^{8}$.

El tema del traslado de la capitalidad fue el más polémico de todos, el que más actuaciones y problemas causó no sólo a la diócesis sino a la provincia entera, ya que la publicación de esta norma, y todas las gestiones que el ayuntamiento de Logroño realizó con tal fin, resultaron insuficientes para llevar a cabo el traslado. Nadie pensó que el cabildo calagurritano, que debía aprobar la traslación de la silla episcopal, se iba a oponer una vez que ellos mismos lo habían aceptado. Y ninguna norma establecía que, tras aprobar el traslado a Logroño, estaban obligados a hacerlo. Un estudio muy completo del Concordato y cómo afectó a la diócesis de Calahorra lo publicó Ángel José Ochoa Alfaro en el número 3 de la revista Kalakoricos en $1998^{9}$.

Francisco Enríquez Ferrer (1811-1870) fue un arquitecto natural de Granada, donde estudió pintura en el taller de su padre, el pintor Francisco Enríquez García, que fue director de pintura de la Academia de Bellas Artes de Granada. A pesar de estar continuamente presenciando los trabajos de su padre y escuchando consejos sobre pintura, sintió mayor atracción por la arquitectura. La Real Academia de San Carlos le expidió el título de arquitecto en 3 de diciembre de 1838. Su carrera se desarrolló fundamentalmente en Granada, Madrid y Toledo. El 6 de febrero de 1859, la Real Academia de Bellas Artes de San Fernando le nombró académico de número. Su vinculación a la Academia de Bellas Artes de San Fernando, a la Iglesia y como miembro de la Comisión Central de Monumentos desde 1848, le llevó a informar sobre las restauraciones y reformas de iglesias y catedrales hasta su muerte, entre ellas, la catedral de León o la que habría de ser catedral de Logroño, la iglesia de Santa María de la Redonda ${ }^{10}$.

La propuesta del arquitecto granadino contemplaba una reforma de la iglesia y la construcción de un nuevo palacio episcopal -edificio estudiado por María Inmaculada Cerrillo Rubio ${ }^{11}$-. Fue presentado el 29 de diciembre de 1853 con planos de 30 de junio y aprobado por la Real Academia de San Fernando en junta general celebrada el 9 de abril de $1854^{12}$. Consta de siete planos de diversos

8. SÁINZ RIPA, Eliseo, Santa María de la Redonda. De Iglesia parroquial a iglesia concatedral. Siglos XII-XX, Logroño, Instituto de Estudios Riojanos, 1992, 2aa ed. corr. y aum. 2002, p. 219.

9. OCHOA ALFARO, Ángel José, "El Concordato de 1851 y sus consecuencias en la Diócesis de Calahorra y La Calzada", Kalakoricos, 3, 1998, pp. 169-183.

10. Escenas contemporáneas. 1860 , nº 3 .

11. CERRILLO RUBIO, María Inmaculada, "Arquitecturas descritas, arquitecturas dibujadas: proyectos en el solar del palacio del obispo", en Investigación humanística y científica en La Rioja: homenaje a Julio Luis Fernández Sevilla y Mayela Balmaseda Aróspide, Logroño, Instituto de Estudios Riojanos, 2000, pp. 293-306.

12. Archivo Municipal de Logroño (en adelante AML), Leg. 122/1. Expediente de traslación de la Silla Episcopal. 1824-1906. En "1852. Informe sobre la traslación de la silla episcopal de Calahorra a Logroño". 


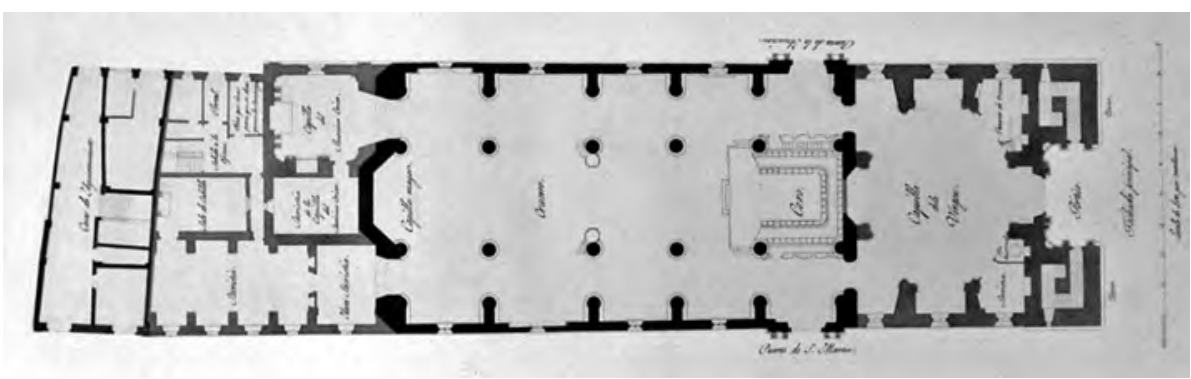

Lámina 1. Planta del templo de Santa María la Redonda de Logroño y de las casas contiguas. Francisco Enríquez Ferrer. Madrid, 30 de junio de 1853. En Archivo Municipal de Logroño, Planos de la Catedral de Logroño (Sin signatura), pág. IV.

tamaños encuadernados en piel con unas dimensiones de $543 \times 750 \mathrm{~mm}$. y se conserva en el archivo de la unidad de arquitectura del ayuntamiento de Logroño ${ }^{13}$. En la primera página se puede leer "Planos del proyecto de habilitación del templo de Santa María la Redonda en Logroño para que sirva de Catedral. Ejecutado en virtud de real orden fecha 24 de Mayo de 1852. Por Don Francisco Enríquez Ferrer". Además de la planta de la Redonda en el momento de su visita a Logroño (Lám. 1) y un dibujo de su fachada, incluye un plano de la iglesia de Santiago y varios sobre la modificación de la primera. Los planos están acompañados de una memoria ${ }^{14}$ y el presupuesto de las obras ${ }^{15}$.

Las reformas (Lám. 2) afectaban fundamentalmente a la cabecera del templo, donde estableció la construcción de un deambulatorio que enlazase las dos naves laterales y que sirviese para que pasaran por él las procesiones claustrales, y que así pudiesen dar la vuelta entera a todo el interior del templo. Para ello, proyectó dos grandes arcos que conectaban las naves laterales con la capiIla del Santo Cristo, la antesacristía y la zona que se encontraba detrás del altar mayor. De esta forma, esa zona se convertiría en un espacio único en el que se ubicaría la capilla del Santo Cristo, lugar al que se trasladaría el sepulcro del obispo Pedro González del Castillo y se construiría una nueva capilla en el lado

13. AA. VV., Logroño en sus documentos, 1095-1995, Logroño, Ayuntamiento de Logroño, 1995 , p. 85.

14. AML, Leg. 122/1. Expediente de traslación de la Silla Episcopal. 1824-1906. En "1852. Informe sobre la traslación de la silla episcopal de Calahorra a Logroño".

15. El presupuesto total de de las obras que debían realizarse en el templo era de 711.959 reales 25 maravedíes de vellón, incluyendo los trabajos de albañilería, honorarios del arquitecto, pintado de puertas y ventanas, vidrieras, el retablo y altar de la nueva capilla lateral y mobiliario para la nueva antesacristía (armarios de nogal). El proyecto fue bien acogido por las autoridades civiles y eclesiásticas, pero parece que la falta de fondos impidió el comienzo inmediato de las mismas (AML, Leg. 122/1). 


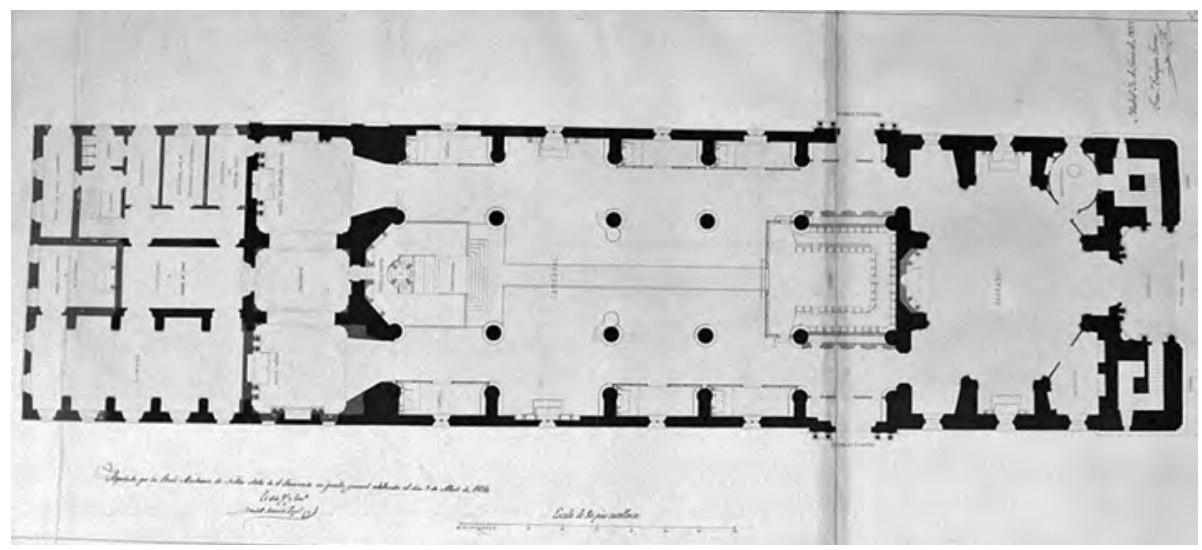

Lámina 2. Modificación de la planta de Santa María la Redonda de Logroño proyectada por Francisco Enríquez Ferrer. Madrid, 30 de junio de 1853. En Archivo Municipal de Logroño, Planos de la Catedral de Logroño (Sin signatura), pág. V.

contrario, ambas cubiertas por cúpula circular. Así, quedaría un espacio entre ambas que se cubriría con una cúpula elíptica. Para construir la girola y poder dar más espacio a las sacristías, sala capitular, oficinas y otras dependencias, solicitó, en el informe que acompañaba a los planos, que se agregase el edificio contiguo a la iglesia que era propiedad del ayuntamiento, donde se ubicarían las oficinas accesorias al templo. Debido a estas obras, se derribaría el muro existente entre la capilla del Santo Cristo y la sacristía de esta capilla, que desaparecería. Además, en este lugar se encontraba el sepulcro del obispo, por lo que Enríquez Ferrer planifica su traslado al muro sur. La ejecución de las obras proyectadas también implicaría el muro que separaba esta sacristía con la antesacristía, que se encontraba al noreste del templo. Así, tras el derribo de estos muros, quedaría un espacio diáfano por el que pudieran pasar las procesiones, tal y como había propuesto el arquitecto. Otra modificación que propuso Enríquez Ferrer fue trasladar el retablo que se encontraba en Santa María de Palacio y que, en un principio, se había hecho para la Capilla Mayor de la Redonda a esta iglesia. A cambio, el retablo que estaba en la Redonda se trasladaría a Palacio. Asimismo, proyectó una ampliación del presbiterio construyendo un tabernáculo aislado, enlazarlo con el coro por medio de una doble verja de hierro poco elevada y otras pequeñas modificaciones.

En los pies de la iglesia, propuso acondicionar como baptisterio un espacio que hasta el momento utilizaban de trastero, y que se trasladase allí la pila bautismal que se encontraba junto a la sacristía de la capilla de Nuestra Señora de los Ángeles.

Completan el proyecto un plano de la fachada lateral sur del templo y una sección longitudinal de la misma en la que se muestra una vista de cómo que- 


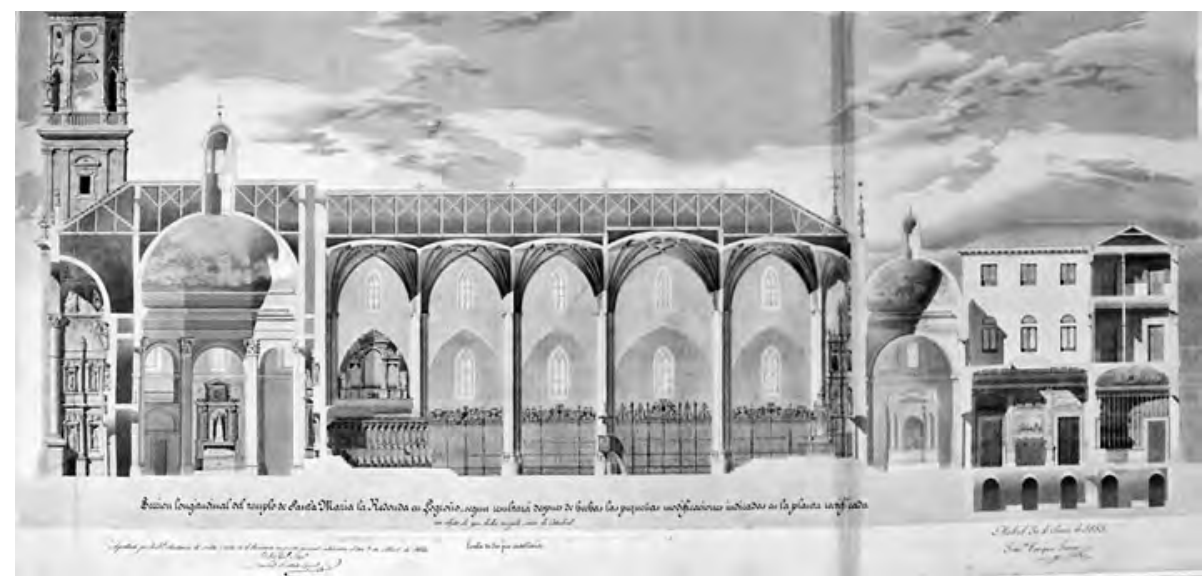

Lámina 3. "Sección longitudinal del templo de Santa María la Redonda en Logroño, según resultará después de hechas las pequeñas modificaciones indicadas en la planta rectificada con objeto de que dicho templo sirva de Catedral". Francisco Enríquez Ferrer. Madrid, 30 de junio de 1853 En Archivo Municipal de Logroño, Planos de la Catedral de Logroño (Sin signatura), pág. IX.

daría el templo unas vez realizadas las reformas de Enríquez Ferrer dibujada con gran minuciosidad por el arquitecto y que evidencia su formación inicial como pintor (Lám. 3).

En 1860, el arquitecto manifestó su deseo de dirigir unas obras que aún no habían empezado y solicitó que se le abonasen los 12.000 reales que se le debían por sus honorarios ${ }^{16}$. Por su parte, el ayuntamiento de Logroño, en sesión ordinaria de 15 de diciembre de $1860^{17}$, acordó pagarle esa cantidad que se le debía al arquitecto en tres plazos que no cumplirán porque el gobernador provincial no autorizó la formación de un presupuesto adicional que asumiese la deuda. En marzo de 1861 informaron a Enríquez Ferrer del retraso de los pagos, que se efectuarían de una vez en enero de 1862. El 4 de abril de 1862, el arquitecto envió una carta a Donato María de Adana, alcalde de Logroño en aquel momento, agradeciéndole el pago de los 12.000 reales que le debían y volvió a manifestar su deseo de dirigir unas obras que aún no habían comenzado.

En mayo de ese mismo año -1862- continuaban las gestiones para comenzar las obras de Santa María de la Redonda. Tadeo Salvador se reunió en Madrid

16. AML, Leg. 122/1. Expediente de traslación de la Silla Episcopal. 1824-1906. En "186061 Cartas" se conserva la carta de Francisco Enríquez Ferrer dirigida al alcalde de Logroño solicitando que se le abonen sus honorarios por el proyecto de reforma de Santa María de la Redonda y de construcción de un Palacio Episcopal.

17. Ibídem. 
con Francisco Enríquez Ferrer para informarse sobre los trámites necesarios para reparaciones y nuevas construcciones de edificios eclesiásticos según un nuevo Real Decreto aprobado el 4 de octubre de $1861^{18}$. Según este decreto, el Ministerio de Gracia y Justicia era el organismo encargado de financiar las obras de reparación y nuevas construcciones de edificios eclesiásticos con la única condición de que se formase un pliego de condiciones para la ejecución de la obra en subasta pública, que el propio arquitecto se ofreció a redactar para ayudar a que comenzasen unas obras que deseaba dirigir, como volvió a manifestar en una nueva carta dirigida al alcalde de Logroño. En octubre de 1864 se realizaron, desde el ayuntamiento de Logroño, una serie de gestiones para llevar los planos al Ministerio de Gracia y Justicia para iniciar su ejecución ${ }^{19}$.

Mientras tanto, el nuevo obispo Antolín Monescillo y Viso (obispo de Calahorra entre 1861 y 1865) se ocupó preferentemente de levantar la nueva diócesis vitoriana dejando de un lado el asunto de la capitalidad. Su sucesor, Fabián Sebastián Arenzana y Magdalena, de origen calagurritano, no era partidario del traslado. Además, en España, se vivieron unos años de inestabilidad política tras la revolución de 1868 que no favorecieron a la agilización del asunto. Con la Restauración y la vuelta a la normalidad política, las autoridades locales logroñesas retomaron el tema del traslado, sin obtener una respuesta definitiva de parte del gobierno central. Francisco Enríquez Ferrer murió en 1870 sin cumplir su deseo de dirigir unas obras que aún no habían comenzado.

Dos motivos retrasaron fundamentalmente las obras proyectadas por Enríquez Ferrer: la economía referida a las obras y la situación canónica en la que quedarían los derechos adquiridos de los miembros del cabildo logroñés. Como intento de solución al primer problema, Maximiano Hijón ${ }^{20}$ presentó el 6 de noviembre de 1880 un segundo proyecto con el objetivo de reducir costes, compuesto por un presupuesto de cantidades que podían reducirse respecto al de Enríquez Ferrer y de otras medidas con el mismo fin ${ }^{21}$.

La propuesta de Hijón obedecía, por un lado, al gran interés que el ayuntamiento tenía en las obras y en el traslado de la silla episcopal de Calahorra a Logroño, y por otro, a la falta de fondos para ejecutarlo.

Junto a él, Maximiano Hijón explica lo que tituló como "economías que podrían hacerse al presupuesto formado en 29 de Diciembre de 1853 para con-

18. Gaceta de Madrid, no 279, de 06.10.1861, pp. 1-2. Real decreto de 4 de octubre dictando disposiciones acerca de la distribución de fondos aplicados a la edificación y reparación de los templos catedrales, colegiales y parroquiales, de los palacios episcopales, de los seminarios conciliares y de las iglesias y casas de religiosos-as, con lo demás que expresa.

19. AML, Leg. 122/1. Expediente de traslación de la Silla Episcopal. 1824-1906.

20. Arquitecto Diocesano hasta 1881.

21. Hijón propuso un nuevo presupuesto que supondría la reducción de 465.083 reales y 38 céntimos respecto al de Enríquez Ferrer. 
vertir en Catedral el templo de Santa $M^{a}$ de la Redonda de esta ciudad de Logroño", donde expone los motivos que según su criterio producirían la reducción del coste del primer proyecto acompañado de un cálculo de esas economías.

Según el arquitecto, eran cuatro las causas que producirían el abaratamiento del primer importe presentado por Enríquez Ferrer en 1853: que el ayuntamiento cediera gratis el edificio de su propiedad necesario para la ampliación del templo y sus dependencias; que se suprimiera la construcción de los sótanos proyectados por los problemas de humedad del subsuelo; que aplazaran el intercambio de retablos entre Santa María de la Redonda y Santa María de Palacio para otro momento más abundante en fondos; y, por último, que pospusieran también el traslado del baptisterio.

Asimismo, este segundo proyecto de Maximiano Hijón incluye un presupuesto de las obras necesarias para llevar a cabo la primera parte del inicial de Enríquez Ferrer de 1853. Las obras que se valoran en dicha partida son la construcción de la girola y los dos nuevos arcos que darían acceso a ella a través de las naves laterales, reforma del tejado y colocación de linternas de luces y ventilación, la ampliación del presbiterio, la construcción de un tabernáculo y de un nuevo retablo semejante al de la capilla del Santo Cristo, el traslado del sepulcro del obispo González del Castillo, verjas y rejas, reconstrucción de la escalera de acceso al edificio de oficinas y otras dependencias, construcción de puertas y ventanas necesarias así como la reforma de las existentes, pintar y empapelar espacios nuevos y restaurar los antiguos ${ }^{22}$.

Finalmente, esta modificación propuesta por Hijón tampoco se llevó a cabo y se realizó un tercer proyecto, que fue el definitivo. Los trámites que dieron lugar a la elaboración del mismo comenzaron hacia 1882 por iniciativa del ayuntamiento de Logroño, que, treinta años después de la firma del Concordato, parecía el único interesado en continuar con el traslado. El 16 de febrero, este consistorio envió una carta al Ministro de Gracia y Justicia solicitando que se retomase el tema del traslado de la silla episcopal ${ }^{23}$. Este documento recoge todos los pasos que se habían dado con tal fin desde el Concordato de 1851, desde el primer informe emitido por el ayuntamiento ese mismo año proponiendo Santa María de la Redonda como el edificio más adecuado para el nuevo fin, hasta la visita de Francisco Enríquez Ferrer en 1853 y la gran insistencia e interés con el que siempre habían trabajado en Logroño para que el traslado de la sede episcopal a esta ciudad se convirtiese en una realidad ${ }^{24}$. Además de esta petición al Ministerio, el ayuntamiento de Logroño aprobó nuevos presupuestos para su catedral que no hicieron más que alargar un problema que el nuevo gobierno y la Igle-

22. La suma total del presupuesto es de 260.155 reales.

23. AML, Leg. 122/1. Expediente de traslación de la Silla Episcopal. 1824-1906.

24. Ibídem. 
sia parecían olvidado, porque para esas fechas el Concordato se había quedado obsoleto y la situación política había cambiado desde su firma en $1851^{25}$.

El 8 de abril de 1882 el ayuntamiento se ratificaba en un ofrecimiento que hiciera en 1866 comprometiéndose a realizar las obras por valor de 76.802 pesetas con la condición de que el estado reintegrase dicha cantidad entre los ejercicios de 1882 y $1884^{26}$. Por su parte, el cabildo no estaba tan preocupado por los trabajos y su coste, como de la situación canónica en la que quedarían sus miembros. Cuando el 7 de agosto de 1882 el Ministerio de Gracia y Justicia le pedía un informe sobre el traslado de la silla, su respuesta fue que veía incompatible que en una misma ciudad existiesen una iglesia colegial y otra catedral. Antes de dar una resolución firme se preguntaba si la colegiata de Logroño y su personal irían a Calahorra una vez efectuado el traslado o si se iba a suprimir la colegial incorporando su personal a la catedral, y si iban a coexistir ambas entidades o sus capitulares serían destinados con igual o superior grado a otras diócesis ${ }^{27}$. Finalmente, el gobierno autorizó al ayuntamiento de Logroño para invertir la cantidad de 66.802 pesetas en las obras de Santa María de la Redonda.

La respuesta del ayuntamiento logroñés fue rápida. En sesión ordinaria del 2 de septiembre de 1882 decidieron encargar el proyecto facultativo a los arquitectos Maximiano Hijón, Francisco de Luis y Tomás y Luis Barrón ${ }^{28}$ y formaron una comisión para gestionar en Madrid el despacho de algunos asuntos pendientes de resolución ${ }^{29}$.

El nuevo proyecto fue presentado el 18 de noviembre de ese mismo año ${ }^{30}$, compuesto por una memoria descriptiva, los planos, las condiciones generales, económicas, de subasta y facultativas, y, por último, el presupuesto ${ }^{31}$. En realidad, es una modificación del presentado por Enríquez Ferrer pero con costes más reducidos en la misma línea que había propuesto uno de los tres arquitectos, Maximiano Hijón, en $1880^{32}$.

25. OCHOA ALFARO, Ángel José, "El Concordato de 1851 y sus consecuencias en la Diócesis de Calahorra y La Calzada", Kalakoricos, 3, 1998, pp. 181.

26. SÁINZ RIPA, Eliseo, Santa María de la Redonda. De Iglesia parroquial a iglesia concatedral. Siglos XII-XX, Logroño, Instituto de Estudios Riojanos, 1992, 2ª ed. corr. y aum. 2002, p. 219.

27. Ibídem, p. 220.

28. En 1882, Arquitecto Municipal, Provincial y Diocesano, respectivamente.

29. Boletín Oficial de la Provincia de Logroño, no 89, 12.10.1882, pp. 2-3.

30. Ibídem, no 143, 14.12.1882, p. 4.

31. Archivo Diocesano de Calahorra (en adelante, ADC), Leg. 19/112/4, Colegiata de Santa María de la Redonda de Logroño (1882 y ss.). Incluye proyecto para convertirla en catedral, planos, correspondencia y otros documentos.

32. El presupuesto de Enríquez Ferrer ascendía a la cantidad de 711.959 reales con 25 maravedíes, equivalentes en 1882 a 177.994 pesetas y 24 céntimos, mientras que en el nuevo proyecto, por petición expresa del ayuntamiento, no debía exceder la cantidad de 66.802 pesetas. Esto suponía una reducción de 111.192 pesetas y 24 céntimos, es decir, que la nueva reforma costaría menos del $50 \%$ respecto a lo estimado en 1853. Finalmente, el presupuesto 
Lámina 4. Planta de la reforma de Santa María de la Redonda.

Maximiano Hijón, Francisco de Luis y Tomás y Luis Barrón. Logroño, 18 de Noviembre de 1882. En Archivo

Diocesano de

Calahorra, Leg.

19/112/4, Colegiata de Santa María de la Redonda de Logroño (1882 y ss.).

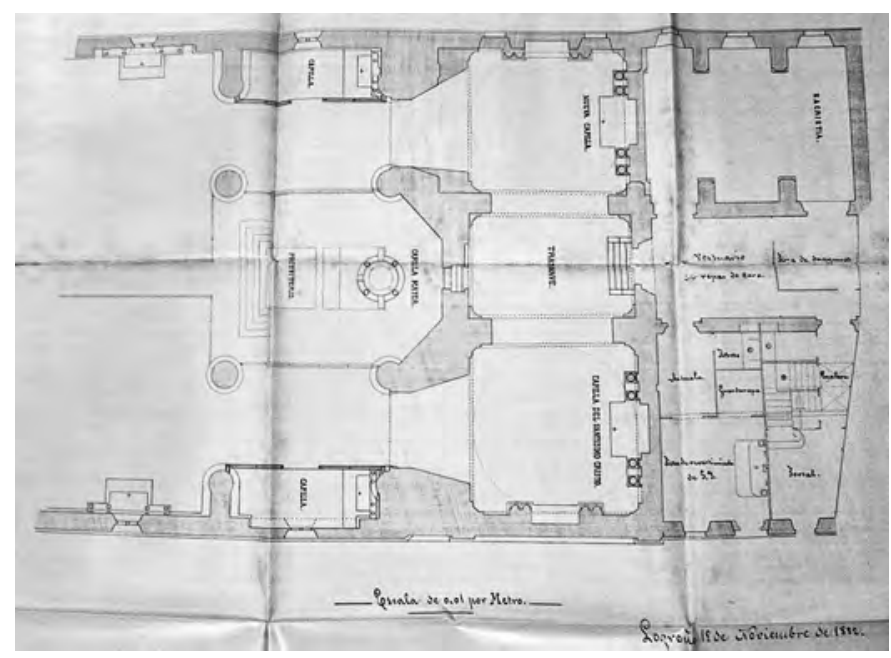

En las condiciones económicas del proyecto se establecía que el presupuesto de contrata y base para subasta era de 74.120 pesetas y 45 céntimos y se concedía un plazo de diez meses para terminar las obras. Los pagos se harían mensualmente por medio de libramientos expedidos por el presidente de la Junta Diocesana, satisfaciéndose su importe por el depositario de la misma previa certificación valorada expedida por duplicado por el Arquitecto Director en la que se acreditaba que quedaban garantizados los intereses de la Administración con el de las obras ejecutadas. Las certificaciones deberían expedirse en los cinco primeros días del mes siguiente a aquél en que hayan sido hechas las obras que comprendan, remitiéndose un ejemplar de ellas por conducto de la Junta Diocesana al Ministerio de Gracia y Justicia para que en su vista se hiciese la consignación de su importe.

La reforma afectaba a la cabecera de la iglesia (Láms. 4, 5 y 6), no variando mucho de lo que había propuesto Francisco Enríquez Ferrer en su proyecto de 1853. Tal y como diseñó el arquitecto granadino, los encargados de este nuevo proyecto establecieron la construcción de una girola que permitiese circular por detrás del altar y que comunicase con las naves de la iglesia mediante dos grandes arcos de medio punto abiertos en los antiguos muros que cerraban las naves laterales en la zona del altar.

Como explican los arquitectos en las condiciones facultativas, además de la construcción de estos dos arcos, era necesario desmontar el suelo y enlosado que

presentado por Hijón, De Luis y Tomás y Barrón sobrepasó lo autorizado en 7.318 pesetas y 45 céntimos, que fue aceptado en septiembre de 1883 tras aprobar el ayuntamiento un presupuesto extraordinario (Boletín Oficial de la Provincia de Logroño, no 57, 05.09.1883, p. 3). 
existía entonces en las dependencias de la antigua cabecera y rebajar la rasante al nivel de la general de la Iglesia. Asimismo, se desmontaron las bóvedas de la sacristía y antesacristía, los tejados, parte del de la sacristía actual, parte también de la de la casa del sacristán y el tejado de la antigua capilla del Santo Cristo. Además, proyectaron dos puertas en la capilla central del deambulatorio para ponerlo en comunicación con la nueva antesacristía y Presbiterio, construyendo con cinco peldaños cada una de las dos escaleras para facilitar el acceso a estos últimos. También diseñaron la construcción de las bóvedas semielipsoidales en las capillas central y lateral del deambulatorio.

Otras reformas propuestas fueron la ampliación del presbiterio poniéndole además en comunicación directa con el coro, por medio de la doble verja de hierro; la construcción de un tabernáculo manifestador de madera dorada y un retablo idéntico al de la capilla del Cristo para colocarlo en la nueva capilla lateral del deambulatorio y la traslación del sepulcro del obispo D. Pedro González del Castillo de la capilla del Cristo al muro sur de la misma como ya había propuesto Francisco Enríquez Ferrer en 1853.

En la casa del sacristán, indican, que se construirán varias dependencias y plantean cambiar la fachada sur de esta casa convirtiendo en ventana la puerta y en puerta la ventana más al este que existía en dicha fachada, así como la modificación de la escalera.

Además, el proyecto comprendía la construcción de puertas y pavimentos, pintar al óleo verjas y ensamblajes, empapelar la sala capitular y sacristía del obispo, restaurar las cajoneras de la antesala y sacristía y hacer un recorrido general de todos los tejados de la Iglesia.

Por lo tanto, las obras sólo afectarían a la cabecera de la iglesia y no se contemplaba el intercambio de retablos entre las iglesias de la Redonda y de Palacio ni la modificación de los pies para trasladar el baptisterio que planteaba el proyecto de Enríquez Ferrer de 1853. Otra diferencia era la intervención prevista en el edificio anejo a la iglesia -la casa del sacristán-, más sencilla en 1882, ya que afectaba sólo a la planta baja y a una pequeña parte de la principal con la modificación de la escalera que comunicaba ambas. Desde luego una reforma menos ambiciosa que los tres pisos de dependencias accesorias al templo del primer proyecto.

El 10 de julio de 1883 se publicó en anuncio de la subasta de las obras en el Boletín Oficial de la Provincia de Logroño $^{33}$, adjudicadas a Domingo Calvo por la cantidad de 73.800 pesetas, que debía abonar el ministerio al ayuntamiento a través de la Junta diocesana de reparación de templos. Cada mes los arquitectos municipales revisaban las obras -en aquel momento Francisco de Luis y Tomás y Luis Barrón- y enviaban al alcalde una certificación de las mis-

33. Boletín Oficial de la Provincia de Logroño, no 8, 10.07.1883, pp. 3-4. 


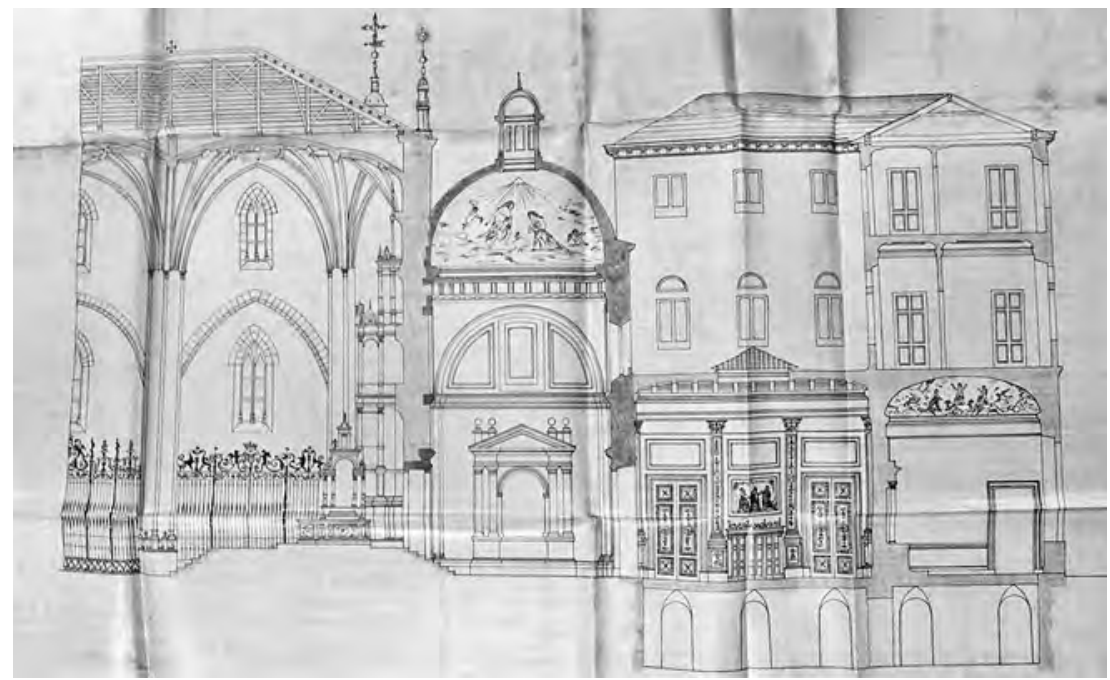

Lámina 5. Sección longitudinal del trasnave. Maximiano Hijón, Francisco de Luis y Tomás y Luis Barrón. Logroño, 18 de Noviembre de 1882. En Archivo Diocesano de Calahorra,

Leg. 19/112/4, Colegiata de Santa María de la Redonda de Logroño (1882 y ss.).

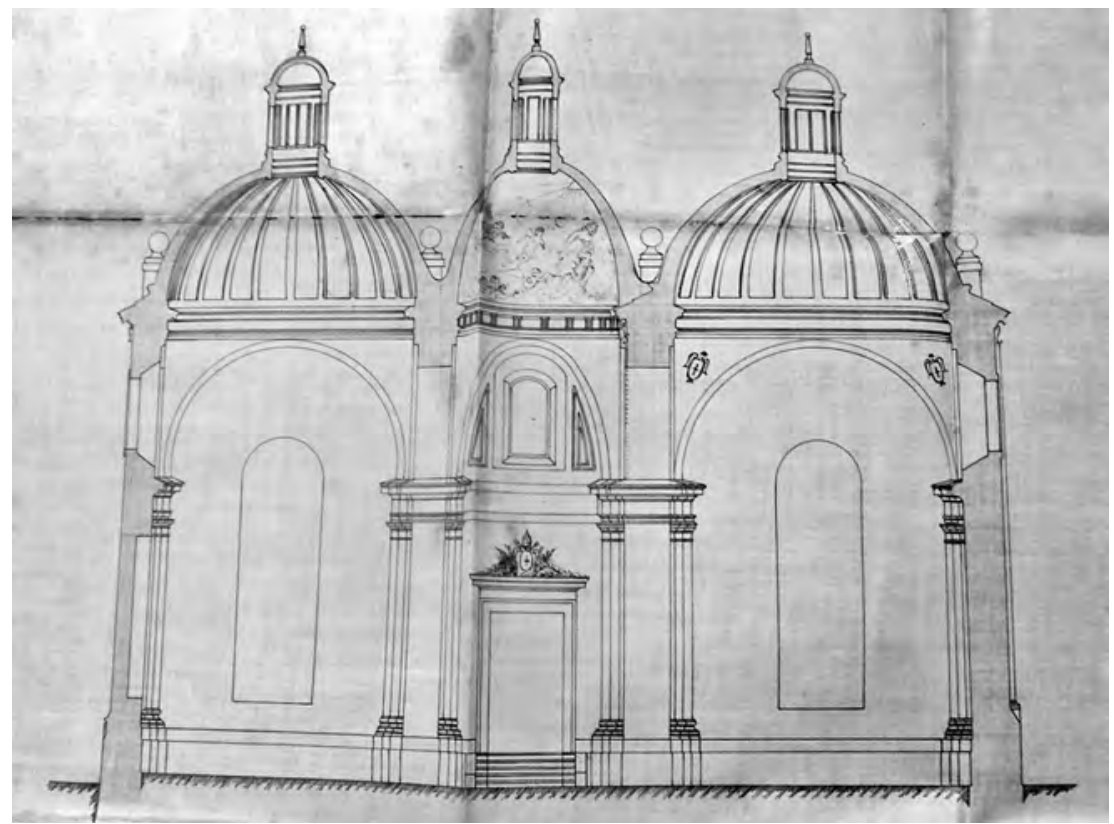

Lámina 6. Sección transversal del trasnave. Maximiano Hijón, Francisco de Luis y Tomás y Luis Barrón. Logroño, 18 de Noviembre de 1882. En Archivo Diocesano de Calahorra, Leg. 19/112/4, Colegiata de Santa María de la Redonda de Logroño (1882 y ss.). 
mas, éste enviaba el certificado a la Junta diocesana de reparación de templos, organismo encargado de remitirlo al Ministerio de Gracia y Justicia y de recibir la respuesta que esta junta transmitía finalmente al ayuntamiento.

En septiembre de 1883 comenzaron las obras eliminando la sacristía de la capilla del Cristo y la antesacristía, que se cubrieron con cúpulas elipsoidales y se construyeron los arcos en las naves laterales que daban paso al nuevo deambulatorio $^{34}$. En diciembre de ese mismo año, se exhumaron los restos del arzobispo Pedro González del Castillo para continuar la reforma de la cabecera ${ }^{35}$. En 1884 proseguían los trabajos porque las fiestas del Corpus y San Bernabé tuvieron que celebrarse en la iglesia del seminario ${ }^{36}$. En marzo de 1885 volvió a utilizarse la nave principal después de año y medio cerrada por obras ${ }^{37}$.

Durante las obras, los pies del templo quedaron incomunicados mediante unos tabicones de la parte de la iglesia que se estaba modificando y se utilizaron el coro y dos capillas laterales con entrada por la puerta de Nuestra Señora de la Asunción (fachada sur) como depósito de ornamentos y objetos de culto ${ }^{38}$. Estos tabiques se echarán abajo año y medio después, cuando se volvió a ocupar la nave principal ${ }^{39}$ a pesar de que la reforma aún no había terminado. Las nuevas dependencias de la casa del sacristán ya debían estar terminadas en 1885, a falta de algunos detalles ${ }^{40}$.

Se conoce el estado en que se encontraba la iglesia hacia 1886 por lo que describe Pedro de Madrazo $^{41}$, quien señala que en la zona del presbiterio se están

34. Archivo Histórico Diocesano de Logroño (en adelante, AHDL), Logroño, Iglesia de Santa María de la Redonda. Libro de Actas Capitulares, no 31, 1874-1884. Caja 113. Fol. 171. En reunión ordinaria del Cabildo del día 7 de septiembre de 1883 acordaron que el día 10 el culto continuase en la capilla de Nuestra Señora de los Ángeles para dar lugar a que los obreros empezasen a trabajar en la capilla del Santísimo Cristo, en la sacristía y en el altar mayor.

35. AHDL, Logroño, Iglesia de Santa María de la Redonda. Libro de Actas Capitulares, no 31, 1874-1884. Caja 113. Fol. 177. Cabildo extraordinario del 20 de diciembre de 1883.

36. SÁINZ RIPA, Eliseo, Santa María de la Redonda. De Iglesia parroquial a iglesia concatedral. Siglos XII-XX, Logroño, Instituto de Estudios Riojanos, 1992, 2ª ed. corr. y aum. 2002, p. 220.

37. AHDL, Logroño, Iglesia de Santa María de la Redonda. Libro de Actas Capitulares, no 32, 1885-1899. Caja 113. Fol. 1. Cabildo extraordinario del 16 de marzo de 1885.

38. AHDL, Logroño, Iglesia de Santa María de la Redonda. Libro de Actas Capitulares, no 31 , 1874-1884. Caja 113. Fol. 167. Cabildo extraordinario del 2 de agosto de 1883.

39. AHDL, Logroño, Iglesia de Santa María de la Redonda. Libro de Actas Capitulares, no 32, 1885-1899. Caja 113. Fol. 1. Cabildo extraordinario del 16 de Marzo de 1885.

40. AHDL, Logroño, Iglesia de Santa María de la Redonda. Libro de Actas Capitulares, no 32, 1885-1899. Caja 113. Fol. 7. Cabildo ordinario del 11 de abril de 1885. Acordaron dirigir una comunicación al contratista de las obras recientemente ejecutadas en la Iglesia, D. Domingo Calvo, reclamándole la cajonería y puertas de las alacenas, previniéndole termine algunos detaIles que faltan en dichas obras.

41. MADRAZO, Pedro de, España, sus monumentos y artes, su naturaleza e historia. III, Navarra y Logroño. Barcelona, Ed. De Daniel Cortezo, 1886, pp. 557-558. 
haciendo unas obras para "acomodar esta Colegiata al nuevo destino de catedral" y que "fisgoneando por entre las vigas y pies derechos que obstruyen la vista, sólo saco en limpio que se trata de dejar exento el altar mayor, libre de toda mole de historiada maquinaria con el nombre de retablo, colocando sobre él un diáfano y sencillo tabernáculo gótico. En el ábside habrá puerta que abrirá paso a la capiIla Ilamada del Cristo, con la cual formará juego otra capilla nueva; y la pieza intermedia que las ha de poner en comunicación una con otra, está ya recibiendo en su bóveda elíptica la decoración pintada con que se ha de inaugurar".

Las obras estaban prácticamente terminadas el 2 de marzo de 1886, fecha en la que se aprueba el acta de recepción provisional de los trabajos, cuya copia se conserva en el ayuntamiento, firmada por Simón Bebrú, presidente del cabildo de la Redonda y delegado del obispo, Ángel Cadarso, arquitecto diocesano de Palencia, Luis Barrón, arquitecto municipal y el contratista Domingo Calvo ${ }^{42}$. Según este documento, sólo faltaría por construir el retablo de la nueva capilla lateral para acabar las obras proyectadas, tal y como advierten en el acta diciendo "que no se ha construido el retablo que figura en las obras diversas de los estados de ubicación, y que había de colocarse en el muro de Oriente de la nueva Capilla lateral del Trasnave, para cuya ejecución se consignaba en el presupuesto la cantidad de cuatro mil quinientas noventa pesetas; por lo cual se hace la recepción provisional de las mismas".

El 27 de enero de 1888, Manuel Alonso Martínez, Ministro de Gracia y Justicia, le envió una carta al alcalde de Logroño diciendo que debían ejecutarse las obras que faltaban para poder aprobar la liquidación de las mismas ${ }^{43}$, a lo que desde el ayuntamiento respondieron que era difícil construir el altar que faltaba para acabar las obras según el proyecto que había servido de base a la subasta, ya que junto a él estaba previsto que se colocase el mausoleo de los Príncipes de Vergara y solicitaron que se aprobase la liquidación final de las obras sin este altar ${ }^{44}$. El Ministerio accedió a esta petición y dio por terminadas las obras el 19 de abril de $1888^{45}$.

Finalmente, el día 9 de marzo de 1889 se emitió el acta de recepción definitiva de las obras, previo reconocimiento del templo, firmada por José Ma García Escudero, abad de la iglesia y representante del obispo; Eduardo Lostán, arquitecto diocesano del arzobispado de Burgos, Luis Barrón, arquitecto diocesano de Calahorra y director de las obras, y el contratista, Domingo Calvo ${ }^{46}$. El

42. AML, Leg. 122/1. Expediente de traslación de la Silla Episcopal. 1824-1906. El acta de recepción provisional original se conserva en el ADC, Leg. 19/112/4.

43. AML, Leg. 122/2. Correspondencia sobre los abonos de las obras de Santa María de la Redonda, con devolución por parte del Estado. 1883-1889.

44. Ibídem.

45. Ibídem.

46. ADC, Leg. 19/112/4, Colegiata de Santa María de la Redonda de Logroño (1882 y ss.). 
mismo día, la Reina aprobó la liquidación final de las obras, tal y como se expresa en una carta recibida en el ayuntamiento de Logroño remitida por el Ministerio de Gracia y Justicia ${ }^{47}$. Por lo tanto, en ese momento en que se daba por terminada la reforma de la entonces colegiata, según los proyectos explicados anteriormente.

En 1893, Francisco Javier Gómez hablaba sobre la transformación que había sufrido el ábside por "las obras para convertir en catedral la antigua colegiata" y decía que donde estuvo la sacristía en el lado opuesto a la capilla del Cristo se eleva un "elegante mausoleo costeado por la Nación, para guardar los restos de los Srmos. Sres. Príncipes de Vergara" ${ }^{48}$.

A pesar de que las obras ya estaban acabadas, el obispo se negaba a trasladarse a Logroño y el cabildo colegial de Logroño se oponía porque conllevaba el traslado de la capitalidad a Logroño. Los sucesos violentos de Calahorra del 23 de junio de 1892 supusieron que la silla episcopal quedase sin obispo titular hasta 1927 y que tanto calagurritanos como logroñeses frenasen cualquier intento definitivo en uno $u$ otro sentido.

Actualmente, se pueden ver las obras que finalmente se ejecutaron en la cabecera de la iglesia, que corresponden al deambulatorio y los dos arcos que dan acceso al mismo y que ocupan el espacio que hasta finales del XIX correspondía a la antesacristía, parte de la sacristía y la primitiva capilla del Santo Cristo, que desde 1889 presenta el aspecto que conocemos hoy en día. En la cabecera aparece la capilla del Santo Cristo modificada según el proyecto de 1882, con la nueva ubicación del sepulcro del obispo González del Castillo en el muro sur de la misma y el retablo del Cristo de los Labradores en el muro este, donde se encontraba antes de la reforma. En el lado opuesto a esta capilla, estaba contemplada la construcción de otra con un nuevo retablo, obra que finalmente no se ejecutó y en cuyo lugar se encuentra ahora la puerta de la sacristía. Poco después de finalizar esta reforma, se colocó el mausoleo de los Príncipes de Vergara en el muro norte de esta nueva capilla, donde hoy se encuentra. Tampoco se colocó la verja que comunicaría el presbiterio con el coro.

Finalmente, y a pesar del esfuerzo, de la ejecución del proyecto de reforma de la Redonda y los muchos intentos por parte del ayuntamiento de Logroño, la silla episcopal nunca se movió de Calahorra. El 9 de marzo de 1959 se reconoció a Santa María de la Redonda como Iglesia Concatedral, dándole a la diócesis la nueva denominación de Calahorra y la Calzada-Logroño.

47. AML, Leg. 122/2. Correspondencia sobre los abonos de las obras de Santa María de la Redonda, con devolución por parte del Estado. 1883-1889.

48. GÓMEZ, F. J., Logroño Histórico. Descripción detallada de lo que un día fue y de cuanto notable ha acontecido desde remotos tiempos hasta nuestros días, Logroño, 1893-1895, p. 656. 